\title{
Flexible remembering
}

\author{
WILMA KOUTSTAAL \\ University of Minnesota, Minneapolis, Minnesota \\ and University of Reading, Reading, England
}

\begin{abstract}
Although highly specific memory is critical in many contexts, the ability to recall knowledge in a more abstract or "gist-based" manner is crucial in allowing transfer of learning to new situations and to complex forms of thought such as using analogies and drawing inferences based on the classification of events and objects. Yet it is unknown whether we can flexibly and intentionally alternate on demand between recollection of gist and recollection of detail, particularly for events from a single context. In a randomly cued test of item-specific versus category-based recognition, younger-and to a lesser extent, older-adults demonstrated such flexible remembering. Gist control was higher in younger than in older adults, and in older adults it correlated with measures of frontal function.
\end{abstract}

Optimal remembering does not always require detailed and specific recollection. Although highly specific memory is critical in many contexts, the ability to recall knowledge in a more abstract or "gist-based" manner is crucial in allowing us to transfer what we learn to new situations (see, e.g., Brainerd \& Reyna, 1990, 1993; Gick \& Holyoak, 1983; Goldstone \& Sakamoto, 2003; McClelland \& Rogers, 2003). Selectively drawing on conceptual or categorical similarities between previous and current experience, while setting aside more fine-grained differences, facilitates many forms of problem solving and complex thought, including effective use of analogy (Gick \& Holyoak, 1983) and making appropriate inferences that are based on the classification of events and objects (Brainerd \& Reyna, 1990, 1993). Impairments in flexible remembering may lead to either hyperspecific or overgeneralized use of knowledge (McClelland \& Rogers, 2003; Ramponi, Barnard, \& Nimmo-Smith, 2004; Williams \& Broadbent, 1986). Awareness of the degree of detail we remember may be central to preventing errors of recall, and to effective judgment and decision making (Goldsmith, Koriat, \& Weinberg-Eliezer, 2002; Reyna, 2004; Yaniv \& Foster, 1995). Yet it is unknown whether we can flexibly and intentionally alternate between recollection of gist and detail on demand (e.g., in response to changing goals), particularly for events that have been encountered in a single spatiotemporal context. ${ }^{1}$

To test whether individuals could intentionally alternate between retrieving detailed information and retrieving gist-based information, participants were first shown pictures of common objects and then tested for their memory of the objects (see Figure 1). Instructional cues to per-

This research was supported by ESRC Grants R000-22-0429 and R000-22-3749. Many thanks to Lesley Tranter for experimental assistance. Correspondence concerning this article should be addressed to W. Koutstaal, Department of Psychology, 247 Elliott Hall, 75 East River Road, Minneapolis, MN 55455 (e-mail: kouts003@umn.edu). form one of the two types of recognition decision were presented immediately before, and concurrently with, the presentation of each object and varied in a pseudorandom and unpredictable manner. For some objects, participants were asked to select "old" only if they had encountered exactly the same object earlier (item-specific recognition). For other objects, they were asked to select "old" if they had encountered either the same object or another object of that same general category (category-based recognition; see Figure 1). Test items included initially shown objects (same exemplars), alternate exemplars of those objects (different exemplars), and new objects not related to the initially shown objects (unrelated).

Flexible remembering of gist and of detail was tested in both younger and older adults. Healthy older adults (6075 years old) often respond inappropriately on the basis of categorical or gist-based information. In experimental situations, this gist-based preference leads to older adults making more errors in the form of false positive or false recognition responses to items that are similar, but not identical, to previously encountered items. Age-related increases in such gist-based errors have been observed for a wide array of materials, including semantically related word pairs (see, e.g., Rankin \& Kausler, 1979), sets of associatively related words (e.g., Tun, Wingfield, Rosen, \& Blanchard, 1998), and categorically related common objects (e.g., Koutstaal, 2003), and may also be of concern in many applied situations, for example, the potential for such errors in older physicians (e.g., Eva, 2002), or in eyewitness contexts.

Nonetheless, there is also evidence that altering the way in which recognition memory is asked about, so as to make older adults more aware of the potential for categorybased errors, may reduce the frequency of such errors in older adults. Changing the usual two-choice "old or new?" recognition test query to a more fine-grained, threechoice recognition query, in which individuals are asked to decide whether a given stimulus was old and identical, new but categorically related, or new and unrelated to a 


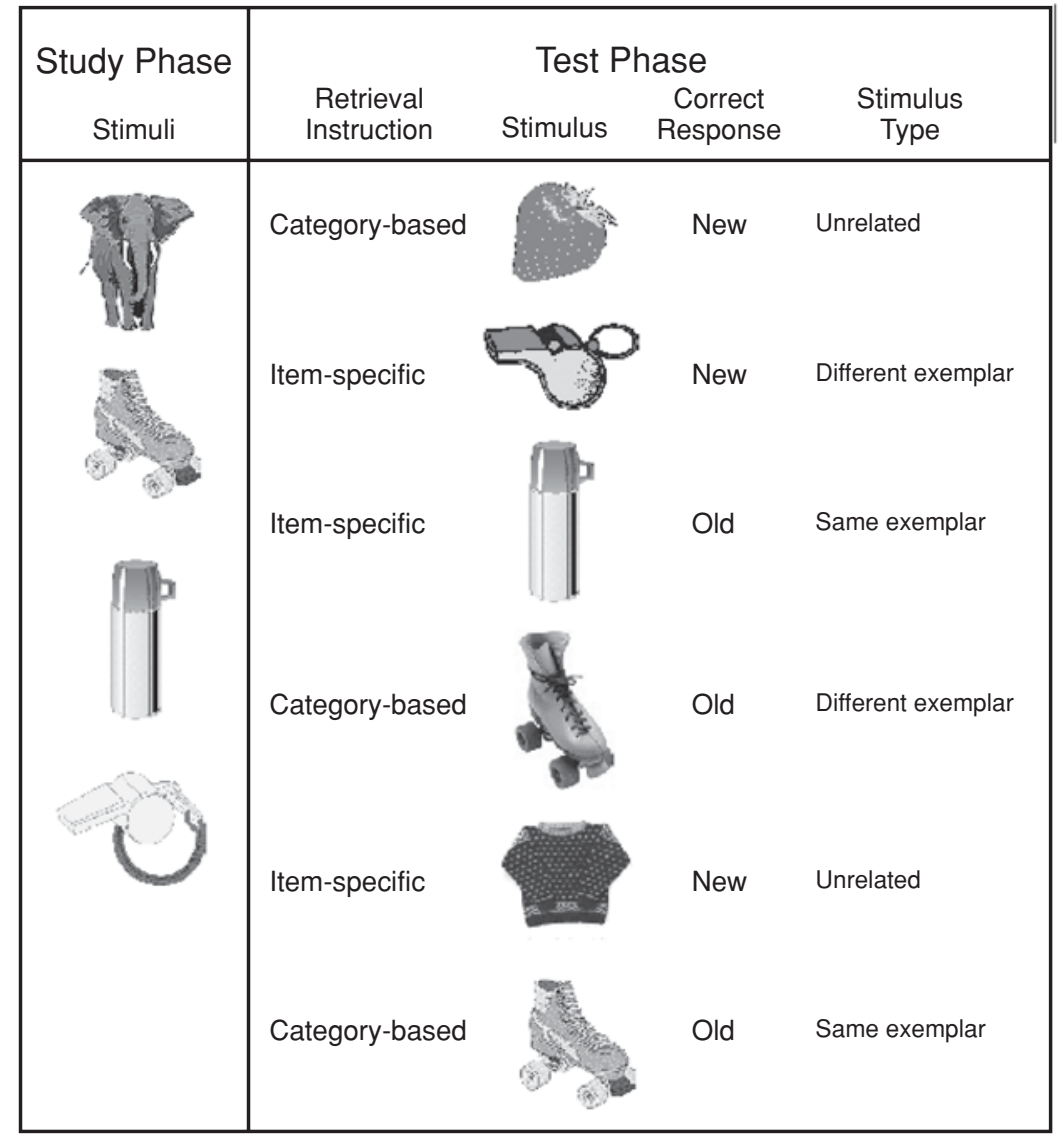

Figure 1. Schematic representation of the study and recognition tasks. For the category-based recognition task, participants were shown several examples of pairs of items that should be designated as belonging to the "same object category," and were instructed that objects that were categorically related would be given the same name. Previous extraexperimental norms showed that, on average, $91 \%$ of the exemplars in each object category were given either exactly the same name, or minor variants (e.g., "TV" vs. "television"). Although here shown in grayscale, stimuli were presented to participants in color.

stimulus they have encountered before, has substantially reduced false recognition errors in older adults (Koutstaal, Schacter, Galluccio, \& Stofer, 1999). Similar findings of reduced errors with the use of more fine-grained recognition test probes have been reported for source memory and misinformation paradigms in younger adults (see, e.g., Lindsay \& Johnson, 1989; Zaragoza \& Koshmider, 1989 ) and also have been found to reduce source misattribution errors (in the form of false fame judgments) in older adults (Multhaup, 1995).

Thus, in addition to the primary aim of determining whether older and younger adults could flexibly and rapidly alternate between a retrieval orientation toward itemspecific and gist-based information "upon cue," a second aim of the experiment was to examine the effects of those explicit cues on false recognition in older adults. Would the explicit and continuously salient requirement to alternate between the two forms of retrieval-like the threealternative recognition query in the earlier experiment- underscore the need to be especially careful not to make categorically based errors in making the item-specific decisions, and thus eliminate the age-related false recognition effect? Both aims would considerably extend our knowledge of how age-related changes affect the "strategic regulation of grain size" (Goldsmith et al., 2002) in recognition decisions.

\section{METHOD}

\section{Participants}

The younger participants were 24 undergraduates from the University of Reading, recruited through posted flyers. Their average age was 20.08 years $(S D=2.39)$; they had, on average, 14.79 years $(S D=1.50)$ of formal education. The older participants were 24 individuals from the University of Reading panel of volunteers of older adults. Their average age was 67.88 years $(S D=4.38)$; they had, on average, 14.54 years $(S D=3.15)$ of formal education. The older and younger groups did not differ in years of education $(F<1)$, but the older adults achieved higher scores than did the younger adults on both the vocabulary subtest of the Wechsler Adult 
Intelligence Scale-Revised (WAIS-R; Wechsler, 1981) $[M=56.88$ vs. $\left.50.79 ; F(1,46)=7.38, M S_{\mathrm{e}}=60.19, p=.009\right]$ and the National Adult Reading Test (Nelson, 1982 ) $[M=39.25$ vs. $30.17 ; F(1,46)=$ $\left.16.92, M S_{\mathrm{e}}=58.52, p=.0002\right]$. All of the participants reported normal or corrected-to-normal vision and color vision and were native speakers of English. Additionally, all of the participants were screened for depression using the Brief Symptom Inventory; those who had scores of 11 or higher on the depression items (Derogatis $\&$ Melisaratos, 1983) were excluded.

The older adults were also screened for several medical conditions that may interfere with cognitive function. They were excluded if they had experienced a vascular incident or major vascular surgery, loss of consciousness lasting more than a few minutes, or exposure to chemotherapy. They were also excluded if they were hypertensive and either were untreated for this or had delayed the onset of recommended treatment. All the older adults achieved scores of 25 or higher (out of a total of 30) on the Mini-Mental State Examination (Folstein, Folstein, \& McHugh, 1975; see Lezak, 1995, for a discussion). Individuals participated either for course credit or in return for a small monetary remuneration.

\section{Stimulus Materials}

The stimuli were colored photographs or detailed line drawings of common objects or animals (see Figure 1). There were a total of 240 object pairs (plus practice items); 120 items ( 1 each from 120 pairs) were presented at study. The test consisted of 360 items, including 120 items from each of three item types: previously presented items (same exemplars), categorically related items (different exemplars), and entirely new (unrelated) items. The items presented at study versus at test, and the type of test probe to which they were assigned (item-specific or category-based), were counterbalanced across participants, and any given item was tested only once per participant. Items of each type and the type of test probe (item-specific or category-based) occurred in a pseudorandom order, with equivalent numbers of each item and test type across each sixth of the test. For any one participant, the type of test probe was held constant for a given exemplar pair (e.g., Umbrella 1 and Umbrella 2 would both be tested either using item-specific or category-based probes). ${ }^{2}$ Brief breaks were given after each third of the test. Stimuli were presented on a Macintosh computer with a color monitor, and the participants indicated their responses using the keyboard.

\section{Procedure}

All of the participants were tested individually after they provided informed consent. The experiment consisted of two separate phases: First came an encoding phase, which was followed by the episodic recognition test. In the encoding phase, the participants performed a size-judgment task, in which they indicated whether the real-world referent of the object shown was larger than a 13-in. box (an example box was provided; objects were presented for $2 \mathrm{sec}$ ). This incidental encoding task was followed by the episodic recognition test. Participants were informed of the two types of recognition decisions that they would be asked to make, and were told that the type of decision required would be indicated by an instruction cue, presented immediately before, and concurrently with, the presentation of each object, stating either "Identical" or "Conceptual." Examples of identical and conceptually related items were provided. After completing the recognition test, the participants were debriefed.

\section{Experimental Design}

Participant age (older or younger) was a between-subjects variable; both test type (item-specific or category-based probe) and item type (same exemplar, different exemplar, and unrelated) were manipulated within subjects. The primary dependent measures were two measures of sensitivity $\left(A^{\prime}\right)$ and corresponding measures of response bias $\left(B_{D^{\prime \prime}}\right)$ that were especially relevant in evaluating flexible remembering. These measures (calculated as described in Koutstaal
\& Schacter, 1997) were (1) measures of sensitivity and response bias to gist, obtained by comparing "old" responses to different exemplars versus "old" responses to new unrelated items, termed $A^{\prime}-$ Gist and $B_{D^{\prime \prime}}-$ Gist, respectively, and (2) measures of sensitivity and response bias to fine-grained item-specific information, obtained by comparing "old" responses to same exemplars versus "old" responses to different exemplars, termed $A^{\prime}$-Fine and $B_{D^{\prime \prime}}-$ Fine, respectively. The sensitivity measure $A^{\prime}$ can vary from .00 to 1.00 , with higher values indicating greater sensitivity and chance performance being .50 . The measure of response bias, $B_{D^{\prime \prime}}$, can vary from -1.00 to +1.00 , with negative values representing more liberal, and positive values more stringent, responding. Table 1 further explains the two measures of sensitivity and their interpretation under the two types of recognition instructions. Table $2 \mathrm{~A}$ presents the average probability of "old" responses for the two types of recognition, and Tables $2 \mathrm{~B}$ and $2 \mathrm{C}$ present the means for the sensitivity and response bias measures.

\section{RESULTS}

\section{Measures of Sensitivity and Response Bias}

Analyses showed that both age groups could flexibly and effectively alternate between the two types of recognition decision. Congruent with the instructions, sensitivity to gist $\left(A^{\prime}-\right.$ Gist $)$ was lower under item-specific (.68) than under category-based $(.86)$ instructions $\left[F(1,46)=182.79, M S_{\mathrm{e}}=\right.$ $.004, p<.0001$, for the effect of test type]; see Figure 2, left panel. Older and younger adults showed high and equivalent levels of gist sensitivity (.86) when intentionally responding on the basis of category information. However, older adults were less able to modulate responding when item-specific decisions were needed; on the item-specific probes, older adults (.74) showed greater - and now inappropriate - gist sensitivity than did younger adults $(.63)[F(1,46)=18.23$, $M S_{\mathrm{e}}=.004, p<.0001$, for the age $\times$ test type interaction]. The age-related difference in gist-based responding under conditions when such responding was appropriate (under the category-based instructional cues) versus when it should be suppressed (under the item-specific instructional cues) is shown in Figure 3. The figure presents the distribution of gist control scores for the individual older versus younger adults ( $A^{\prime}$-Gist for the category-based test minus $A^{\prime}$-Gist for the item-specific test); younger adults showed significantly greater gist control than did older adults.

Similar patterns were observed when sensitivity to same exemplars was compared with sensitivity to different exemplars using the measure $A^{\prime}$-Fine (see Figure 2, right panel). Consistent with the instructions, participants showed reduced sensitivity to the difference between same and different exemplars when asked to make categorybased recognition decisions (.57) as opposed to itemspecific judgments $(.80)\left[F(1,46)=177.85, M S_{\mathrm{e}}=.007\right.$, $p<.0001$, for the effect of test type]. However, whereas the two age groups showed equivalent and relatively low sensitivity to the distinction between same and different exemplars as required on the category-based probes $(.57$ for both groups), older (.75) as opposed to younger (.85) individuals showed reduced fine-grained discrimination between same and different exemplars when required to do so on the identical probes $\left[F(1,46)=7.89, M S_{\mathrm{e}}=\right.$ $.007, p=.007$, for the age $\times$ test type interaction]. 
Table 1

Explication of the Experimental Paradigm and Measures of Sensitivity

\begin{tabular}{|c|c|c|}
\hline & Item-Specific Recognition & Category-Based Recognition \\
\hline Item types & $\begin{array}{l}\text { Same exemplar (e.g., whistle 1) } \\
\text { Different exemplar (e.g., whistle 2) } \\
\text { Unrelated new item (e.g., sweater) }\end{array}$ & $\begin{array}{l}\text { same exemplar (e.g., roller skate 1) } \\
\text { different exemplar (e.g., roller skate 2) } \\
\text { unrelated new item (e.g., strawberry) }\end{array}$ \\
\hline Instructions & $\begin{array}{l}\text { Call "old" only items that are } \\
\text { identical to those shown at study. }\end{array}$ & $\begin{array}{l}\text { Call "old" both items that are identical } \\
\text { to those shown at study and those that } \\
\text { belong to the same object category as } \\
\text { a studied item. (Examples given of } \\
\text { object pairs; objects in the same category } \\
\text { would be given the same name; all items } \\
\text { selected to have high within-pair name } \\
\text { agreement in a previous norming study.) }\end{array}$ \\
\hline \multirow[t]{4}{*}{ Examples } & \multicolumn{2}{|c|}{ Correct Responses } \\
\hline & $\begin{array}{l}\text { Study whistle } 1 \text {; call whistle } 1 \\
\text { "old" (= hit to same exemplar); } \\
\text { call whistle } 2 \text { "new" (= correct rejection } \\
\text { of different exemplar, showing item- } \\
\text { specific differentiation as required). }\end{array}$ & $\begin{array}{l}\text { Study roller skate } 1 \text {; call roller skate } 1 \\
\text { "old" (= hit to same exemplar); } \\
\text { call roller skate } 2 \text { "old" (= hit to } \\
\text { different exemplar, showing correct gist- } \\
\text { or category-based recognition). }\end{array}$ \\
\hline & \multicolumn{2}{|c|}{ Incorrect Responses } \\
\hline & $\begin{array}{l}\text { Designating whistle } 2 \text { as "old" is } \\
\text { incorrect and is a gist-based false } \\
\text { recognition response (failure of } \\
\text { item-specific differentiation). }\end{array}$ & $\begin{array}{l}\text { Designating roller skate } 2 \text { as "new" is } \\
\text { incorrect and is a failure of category- } \\
\text { based recognition (lack of generalization } \\
\text { or "verbatim-exit bias"). }\end{array}$ \\
\hline $\begin{array}{l}\text { Sensitivity } \\
\text { measures } \\
\text { and their } \\
\text { meanings }\end{array}$ & $\begin{array}{l}A^{\prime}-\text { Gist: compares "old" responses to } \\
\text { different exemplars vs. "old" responses } \\
\text { to unrelated items; indexes inappropriate } \\
\text { sensitivity to gist compared to unrelated } \\
\text { items (when gist or coarse-grained } \\
\text { category information should not be used). } \\
A^{\prime}-\text { Fine: compares "old" responses to } \\
\text { same exemplars vs. "old" responses to } \\
\text { different exemplars; indexes ability to } \\
\text { differentiate identical items from } \\
\text { categorically similar items } \\
\text { (when gist should not be used). }\end{array}$ & $\begin{array}{l}A^{\prime} \text {-Gist: compares "old" responses to } \\
\text { different exemplars vs. "old" responses } \\
\text { to unrelated items; indexes now } \\
\text { appropriate sensitivity to gist compared } \\
\text { to unrelated items (when gist or category } \\
\text { information should be used). } \\
A^{\prime}-\text { Fine: compares "old" responses to } \\
\text { same exemplars vs. "old" responses to } \\
\text { different exemplars; now indexes } \\
\text { differential sensitivity to identical items } \\
\text { compared to categorically similar items } \\
\text { ("same-exemplar advantage" or } \\
\text { "verbatim-exit bias") during } \\
\text { category-based recognition (when gist } \\
\text { should be used). }\end{array}$ \\
\hline
\end{tabular}

Although both age groups showed reduced sensitivity to the difference between same and different exemplars on the category-based test, they nevertheless showed significantly greater category-based recognition of same than of different exemplars (one-sample $t$ tests against an expected population value of .50) $[t(23)=4.29, p=$ .0003 for older; $t(23)=4.41, p=.0002$ for younger]. This "same-exemplar advantage" in category-based recognition may partially reflect what has been called a "verbatim-exit bias" (Brainerd \& Reyna, 1993), or a tendency of individuals to make similarity judgments when they should be processing meaning (rather than surface form), and it parallels a similar verbatim advantage observed in children (Reyna \& Kiernan, 1994). ${ }^{3}$

Measures of response bias ( $B_{D^{\prime \prime}}-$ Gist and $B_{D^{\prime \prime}}$-Fine; see Tables $2 \mathrm{~B}$ and $2 \mathrm{C}$ ) for the two corresponding measures of sensitivity showed that both age groups were markedly more conservative on the item-specific than on the category-based tests. However, for $B_{D^{\prime \prime}}-$ Gist, younger adults were more lenient overall (.24 vs. .42 for older adults) $\left[F(1,46)=6.79, M S_{\mathrm{e}}=.12, p=.01\right]$, and, for
$B_{D^{\prime \prime}}-$ Fine, also showed a somewhat more pronounced change in criteria for the two types of test $(.38$ vs. -.82 for younger; .26 vs. -.73 for older) $\left[F(1,46)=4.92, M S_{\mathrm{e}}=\right.$ $.05, p=.03$, for the age $\times$ test type interaction]. Focusing specifically on response criteria for the item-specific tests, older adults showed a trend toward more conservative responding (.94) than did younger adults (.85) on the $B_{D^{\prime \prime}}-$ Gist measure $\left[F(1,46)=3.19, M S_{\mathrm{e}}=.03, p=.08\right]$; on the $B_{D^{\prime \prime}}$-Fine measure, older adults were slightly but nonsignificantly less conservative (.26) than their younger counterparts $(.38)(F=1.6)$.

\section{Gist Control and Frontal Function}

After completion of the experiment reported here, Butler, McDaniel, Dornburg, Price, and Roediger (2004) reported findings demonstrating that age-related increases in false recall for associatively related sets of words were confined to older adults with relatively low frontal lobe functioning. In that study, older individuals with higher frontal lobe function showed levels of false recall similar to those of younger adults. Although we had not collected 
Table 2A

\begin{tabular}{lccccccc}
\multicolumn{8}{c}{ Mean Proportion "Old" Responses } \\
\hline & \multicolumn{2}{c}{ Item-Specific Recognition } & & \multicolumn{2}{c}{ Category-Based Recognition } \\
\cline { 2 - 3 } \cline { 6 - 8 } & Same & Different & New & & Same & Different & New \\
\hline Older & .61 & .24 & .04 & & .86 & .81 & .24 \\
Younger & .72 & .14 & .07 & & .91 & .88 & .31 \\
\hline
\end{tabular}

Note-Same, same exemplar; Different, different exemplar; New, unrelated items. Under item-specific recognition, "old" responses to different exemplars are false recognition responses; under category-based recognition, "old" responses to different exemplars are correct (gist-based) responses.

Table 2B

Measures of Sensitivity and Response Bias to Gist: $A^{\prime}-$ Gist and $B_{D^{\prime \prime}}-$ Gist

\begin{tabular}{lccccc}
\hline & \multicolumn{2}{c}{$\begin{array}{c}\text { Item-Specific } \\
\text { Recognition }\end{array}$} & & \multicolumn{2}{c}{$\begin{array}{c}\text { Category-Based } \\
\text { Recognition }\end{array}$} \\
\cline { 2 - 3 } \cline { 5 - 6 } & $A^{\prime}-$ Gist & $B_{D^{\prime \prime}}-$ Gist & & $A^{\prime}-$ Gist & $B_{D^{\prime \prime}-\text { Gist }}$ \\
\hline Older & .74 & .94 & & .86 & -.10 \\
Younger & .63 & .85 & & .86 & -.38 \\
\hline
\end{tabular}

Note- $A^{\prime}-$ Gist and $B_{D^{\prime \prime}}-$ Gist compare "old" responses to different exemplars versus "old" responses to new unrelated items.

Table 2C

Measures of Sensitivity and Response Bias to Fine-Grained Item-Specific Information: $A^{\prime}-$ Fine and $B_{D^{\prime \prime}}$ Fine

\begin{tabular}{cccccc}
\multicolumn{3}{c}{ Item-Specific Information: $\boldsymbol{A}^{\prime}$-Fine and $\boldsymbol{B}_{\boldsymbol{D}^{\prime \prime}}$-Fine } \\
\cline { 2 - 3 } & \multicolumn{2}{c}{$\begin{array}{c}\text { Item-Specific } \\
\text { Recognition }\end{array}$} & & \multicolumn{2}{c}{$\begin{array}{c}\text { Category-Based } \\
\text { Recognition }\end{array}$} \\
\cline { 2 - 3 } \cline { 5 - 6 } & $A^{\prime}-$ Fine & $B_{D^{\prime \prime}}$-Fine & & $A^{\prime}$-Fine & $B_{D^{\prime \prime}}-$ Fine \\
\hline Older & .75 & .26 & & .57 & -.73 \\
Younger & .85 & .38 & & .57 & -.82 \\
\hline
\end{tabular}

Note- $A^{\prime}$-Fine and $B_{D^{\prime \prime}}-$ Fine compare "old" responses to same exemplars versus "old" responses to different exemplars.

data on a number of the frontal lobe function tests used by those authors, data were available for all 24 older participants for the Controlled Oral Word Association Test (Spreen \& Strauss, 1991; letter "F" only). As can be seen in Figure 4, there was a strong positive correlation between scores on this frontal test of phonemic fluency and gist control among the older adults $[r=.51, z=2.55, p=$ $.01]$. We also had data for all 24 older participants on semantic category fluency (animal names), which has been shown to be influenced by both frontal and temporal lobe function (e.g., Troyer, Moscovitch, Winocur, Alexander, $\&$ Stuss, 1998); there was again a significant positive correlation between this measure and gist control scores $[r=$ $.42, z=2.05, p=.04]$.

\section{DISCUSSION}

These findings demonstrate that both younger and (to a lesser extent) older individuals can flexibly and rapidly alternate between attempts to query memory at a highly specific level and attempts to query memory at a categorical level, even for experiences from a single spatiotemporal context, consistent with theoretical and computational arguments that both forms of remembering are essential to adaptive cognition (Brainerd \& Reyna, 1990; Gick \& Holyoak, 1983; Goldstone \& Sakamoto, 2003; Lamberts,
1994; McClelland \& Rogers, 2003). Yet even though older adults could appropriately alternate between the two forms of retrieval, as indicated by the varying instructional cues on each trial, the explicit and continuously salient requirement to alternate between the two forms of retrieval did not eliminate the age-related increase in gist-based errors on the item-specific recognition trials.

Several further observations might be noted. First, the age-related vulnerability to gist on the item-specific trials was observed even though older adults' response criteria were only slightly and nonsignificantly more lenient on the measure comparing "old" responses to same versus different exemplars ( $B_{D^{\prime \prime}}-$ Fine $)$, and older adults actually showed more conservative criteria on the measure comparing "old" responses to different exemplars versus unrelated items $\left(B_{D^{\prime \prime}}-G i s t\right)$. These findings concur with other studies (e.g., Koutstaal et al., 1999) in suggesting that age-related vulnerability to false recognition is not entirely attributable to differences in response criteria but also derives, in part, from decrements in older adults' ability to intentionally discriminate detailed aspects of studied items from similar-appearing lures (as also shown here in older as opposed to younger adults' significantly reduced sensitivity on the $A^{\prime}$-Fine measure).

Second, this pattern of increased age-related vulnerability to gist on the item-specific probes was observed 

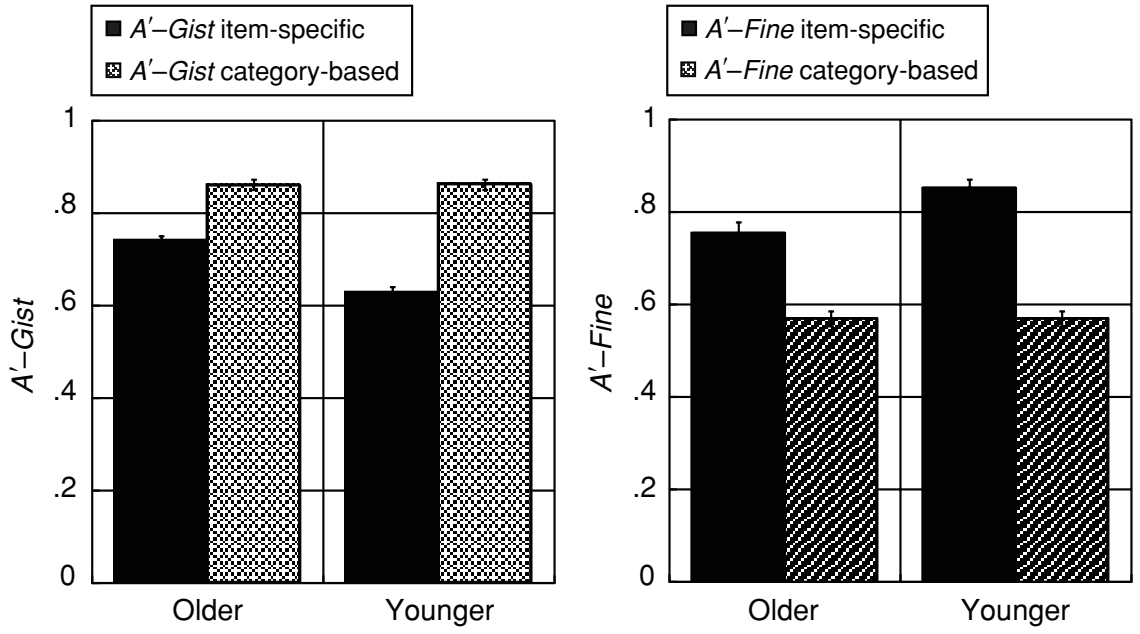

Figure 2. Sensitivity to gist ( $A^{\prime}-$ Gist, left panel) and to fine-grained differences between same and different exemplars ( $A^{\prime}$-Fine, right panel), shown separately by age group (older/ younger) and instructional cue during recognition testing (item-specific/category-based). Error bars show standard errors of the mean.

even though-for items from the very same encoding episode and probed on the very same recognition test but with the category-based instruction - the two age groups showed essentially equivalent ability to respond deliberately or intentionally on the basis of gist information. This demonstrates that, although gist was equally available to both younger and older adults, younger adults were more adept at resisting responding on the basis of gist when reliance on this form of coarse-grained categorical information would be inappropriate.

Third, in contrast to the results for the item-specific probes, the two age groups showed a very similar pattern of preferential recognition of same-exemplar items over different-exemplar items on category-based probes. This outcome (as also found in Koutstaal, 2003) indicates that the older adults do encode at least some perceptual and/ or conceptual details needed to differentiate target items from similar-appearing lures - otherwise, categorical recognition of same and different exemplars should have been equivalent — but they do not (or cannot) always effectively call upon those details in making intentional memory decisions that demand item-specific recollection.

Fourth, the exploratory correlational analyses reported here, showing a positive correlation between measures of verbal fluency and the measure of gist control, suggest that the age-related difference in the intentional use of item-specific information may be especially marked in older individuals with more pronounced decrements in
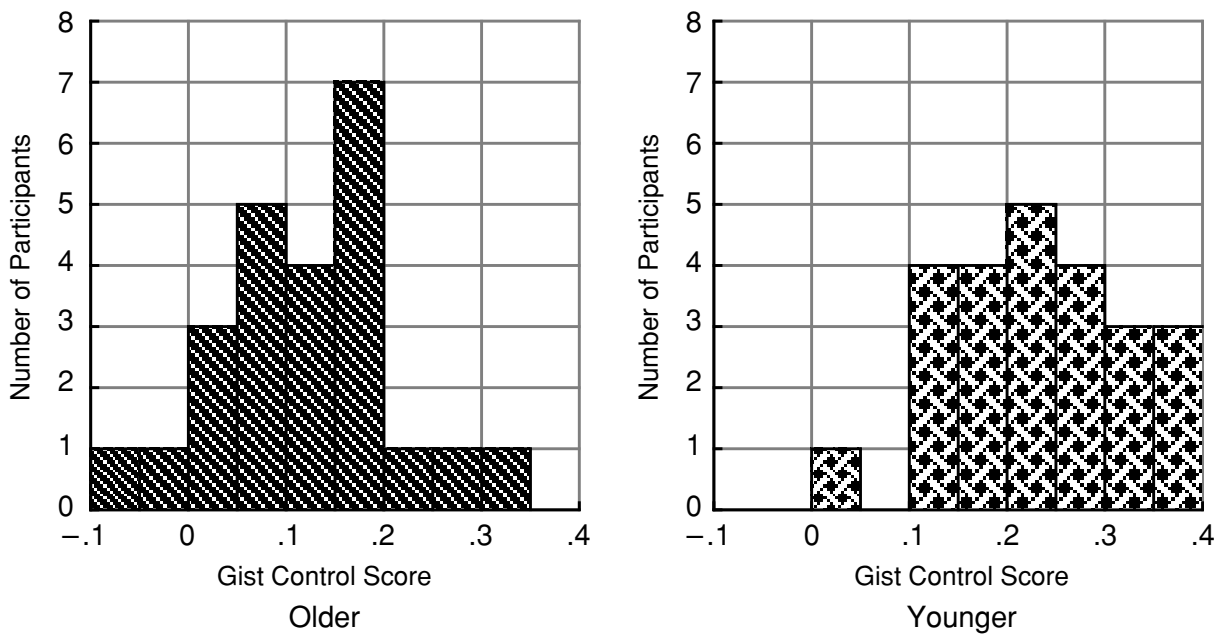

Figure 3. Intentional gist control ( $A^{\prime}$-Gist for category-based minus $A^{\prime}$-Gist for item-specific instructions), shown for individual participants by age group. 


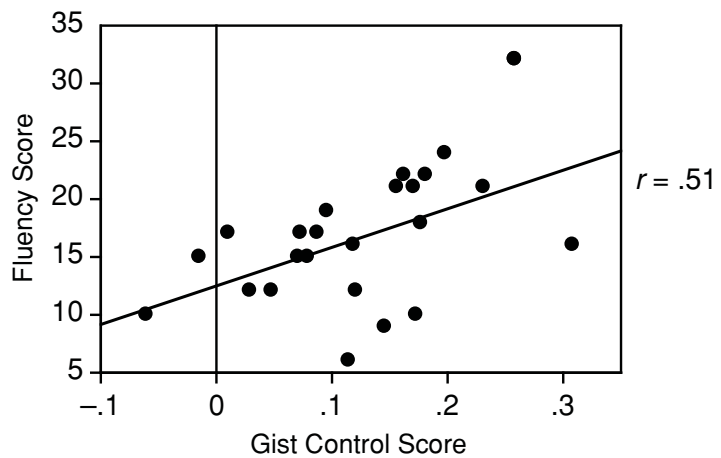

Figure 4. Correlation between intentional gist control $\left(A^{\prime}-G i s t\right.$ for category-based minus $\boldsymbol{A}^{\prime}$-Gist for item-specific instructions) and letter fluency (Controlled Oral Word Association Test; letter "F" only) in the older adults.

frontal lobe functioning (Butler et al., 2004). In addition to being broadly consistent with the findings of Butler et al., these positive correlations are congruent with other neuropsychological findings suggesting that verbal fluency tasks call upon (at least in part) such frontal lobe processes as strategic search, cognitive flexibility, and attention monitoring (see, e.g., Troyer et al., 1998) —all processes important in the present task, which demanded continuous and flexible adjustments in retrieval orientation and appropriate, trial-by-trial monitoring and updating of the task goals. ${ }^{4}$

Finally, although the present results cannot conclusively isolate the cognitive processes leading to older adults' heightened gist sensitivity on the item-specific probes, we showed in recent research (Koutstaal et al., 2003) that agerelated increases in gist-based false recognition are clearly evident only for stimuli with preexisting semantic/lexical representations (e.g., pictures of common objects such as those used here). When the stimuli were, instead, entirely novel items, never previously experienced and without preexisting names or semantic representations, no agerelated increase in false recognition was observed. Taken together with the significant same exemplar advantage shown here for the category-based recognition probes, which demonstrated that older adults had encoded (at least some) exemplar-differentiating details, it appears that, on item-specific tests, older adults often fail to resist endorsing lure items primarily because of semantic/lexical information shared with studied items, as though a study-test match on this basis is a strong neural-network "attractor." Resisting a positive recognition response in the face of such semantic/lexical matches might especially draw on frontal control processes, such as deliberate focused attention and strategic search; furthermore, the "pull" toward responding on the basis of matching semantic/lexical information may be particularly strong in older adults, given their reduced item-specific memory. In younger adults, item-specific memory serves as a more potent - and more flexibly deployed - counterweight to coarser-grained gistor category-based knowledge.

\section{REFERENCES}

Brainerd, C. J., \& Reyna, V. F. (1990). Gist is the grist: Fuzzy-trace theory and the new intuitionism. Developmental Review, 10, 3-47.

Brainerd, C. J., \& Reyna, V. F. (1993). Memory independence and memory interference in cognitive development. Psychological Review, 100, 42-67.

Butler, K. M., McDaniel, M. A., Dornburg, C. C., Price, A. L., \& RoEDIGER, H. L., III (2004). Age differences in veridical and false recall are not inevitable: The role of frontal lobe function. Psychonomic Bulletin \& Review, 11, 921-925.

Derogatis, L. R., \& Melisaratos, N. (1983). The Brief Symptom Inventory: An introductory report. Psychological Medicine, 13, 595605

Eva, K. W. (2002). The aging physician: Changes in cognitive processing and their impact on medical practice. Academic Medicine, 77(10), S1-S6.

Folstein, M. F., Folstein, S. E., \& McHugh, P. R. (1975). Mini-mental state: A practical method for grading the cognitive state of patients for the clinician. Journal of Psychiatric Research, 12, 189-198.

Gick, M. L., \& HolYOAK, K. J. (1983). Schema induction and analogical transfer. Cognitive Psychology, 15, 1-38.

Goldsmith, M., Koriat, A., \& Weinberg-Eliezer, A. (2002). Strategic regulation of grain size in memory reporting. Journal of Experimental Psychology: General, 131, 73-95.

Goldstone, R. L., \& SaKamoto, Y. (2003). The transfer of abstract principles governing complex adaptive systems. Cognitive Psychology, 46, 414-466.

Graham, K. S., Simons, J. S., Pratt, K. H., Patterson, K., \& Hodges, J. R. (2000). Insights from semantic dementia on the relationship between episodic and semantic memory. Neuropsychologia, 38, 313324

KoutstaAl, W. (2003). Older adults encode — but do not always useperceptual details: Intentional versus unintentional effects of detail on memory judgments. Psychological Science, 14, 189-193.

Koutstaal, W., \& Cavendish, M. C. (in press). Using what we know: Consequences of intentionally retrieving gist versus item-specific information. Journal of Experimental Psychology: Learning, Memory, \& Cognition.

Koutstaal, W., Reddy, C., Jackson, E. M., Prince, S., Cendan, D. L., \& SCHACTER, D. L. (2003). False recognition of abstract versus common objects in older and younger adults: Testing the semantic categorization account. Journal of Experimental Psychology: Learning, Memory, \& Cognition, 29, 499-510.

Koutstaal, W., \& Schacter, D. L. (1997). Gist-based false recognition of pictures in older and younger adults. Journal of Memory \& Language, 37, 555-583.

Koutstaal, W., Schacter, D. L., Galluccio, L., \& Stofer, K. A. (1999). Reducing gist-based false recognition in older adults: Encoding and retrieval manipulations. Psychology \& Aging, 14, 220-237.

LAMBERTS, K. (1994). Flexible tuning of similarity in exemplar-based categorization. Journal of Experimental Psychology: Learning, Memory, \& Cognition, 20, 1003-1021.

LeZAK, M. D. (1995). Neuropsychological assessment (3rd ed.). New York: Oxford University Press.

LindSAY, D. S., \& JoHnson, M. K. (1989). The eyewitness suggestibility effect and memory for source. Memory \& Cognition, 17, 349-358.

McClelland, J. L., \& Rogers, T. R. (2003). The parallel distributed processing approach to semantic cognition. Nature Reviews Neuroscience, 4, 310-322.

Multhaup, K. S. (1995). Aging, source, and decision criteria: When false fame errors do and do not occur. Psychology \& Aging, 10, 492497.

Nelson, H. E. (1982). National Adult Reading Test (NART) [Test manual] (2nd ed.). Windsor, U.K.: NFER-Nelson.

Ramponi, C., Barnard, P. J., \& Nimmo-Smith, I. (2004). Recollection deficits in dysphoric mood: An effect of schematic models and executive mode? Memory, 12, 655-670

RANKIN, J. L., \& KAUSLER, D. H. (1979). Adult age differences in false recognitions. Journal of Gerontology, 34, 58-65.

ReYNA, V. F. (2004). How people make decisions that involve risk: A 
dual-processes approach. Current Directions in Psychological Science, 13, 60-66.

Reyna, V. F., \& Kiernan, B. (1994). Development of gist versus verbatim memory in sentence recognition: Effects of lexical familiarity, semantic content, encoding instructions, and retention interval. Developmental Psychology, 30, 178-191.

Spreen, O., \& Strauss, E. (1991). A compendium of neuropsychological tests: Administration, norms, and commentary. New York: Oxford University Press.

Troyer, A. K., Moscovitch, M., Winocur, G., Alexander, M. P., \& Stuss, D. (1998). Clustering and switching on verbal fluency: The effects of focal frontal- and temporal-lobe lesions. Neuropsychologia, 36, 499-504.

Tun, P. A., Wingfield, A., Rosen, M. J., \& Blanchard, L. (1998). Response latencies for false memories: Gist-based processes in normal aging. Psychology \& Aging, 13, 230-241.

WeCHSLER, D. (1981). Manual for the Wechsler Adult Intelligence Scale-Revised. San Antonio, TX: Psychological Corporation.

Williams, J. M. G., \& Broadbent, K. (1986). Autobiographical memory in suicide attempters. Journal of Abnormal Psychology, 95, 144149.

YANIV, I., \& Foster, D. P. (1995). Graininess of judgment under uncertainty: An accuracy-informativeness trade-off. Journal of Experimental Psychology: General, 124, 424-432.

Zaragoza, M. S., \& Koshmider, J. W., III (1989). Misled subjects may know more than their performance implies. Journal of Experimental Psychology: Learning, Memory, \& Cognition, 15, 246-255.

\section{NOTES}

1. Other recent findings (Koutstaal \& Cavendish, in press) of experiments in which individuals were asked to make exclusively itemspecific, or exclusively gist- or category-based recognition decisions over a prolonged period, showed that sustained category-based retrieval impaired subsequent item-specific retrieval. In contrast, no such deficit emerged if individuals engaged in prolonged item-specific retrieval and subsequently made category-based decisions. See Lamberts (1994) for evidence of flexible generalization in exemplar-based categorization judgments, even for items (schematic drawings of individuals' faces) learned in a single spatiotemporal context.

2 . This pairing of category members at the time of testing, and presentation of only one item per category for new unrelated items, may have provided a cue to participants that a semantic category had been previously studied, and this may have slightly inflated the sensitivity measures in comparison with what otherwise would have been observed. However, multiple testing of the unrelated new items from the same semantic category would introduce interpretive difficulties of its own and, especially, would complicate the age-group comparisons because older adults might have particular difficulty in performing the "source monitoring" task of differentiating between categorically related items that were shown at study and categorically related items that had been previously presented as lures during recognition testing. Of the two possible interpretive difficulties, it seemed more important to avoid the latter.

3. Some of the same-exemplar advantage also may derive from differences in how participants named the object exemplars within the pairs; although items were selected to have high within-pair name agreement, such agreement was not $100 \%$, and it varied somewhat by individual.

4. Although the results presented here provide suggestive evidence of the importance of frontal lobe functioning in flexible remembering, constraints on such flexible remembering may also arise from disruptions in semantic and temporal-lobe processes. For instance, in semantic dementia, degradation of the memory representations of semantic concepts arising from progressive atrophy of one or both temporal lobes impairs category-based episodic recognition, so that individuals in the earlier stages of this disorder may accurately recognize same but not different exemplars from studied object categories for which they show impaired knowledge (Graham, Simons, Pratt, Patterson, \& Hodges, 2000). This suggests that recognition normally is supported by both conceptual and perceptual input, and that near-exclusive reliance on exact perceptual input allows only limited — highly specific, but also inflexible-recognition.

(Manuscript received March 20, 2005; revision accepted for publication May 27, 2005.) 